\title{
Research on the Reflection and Construction of Northeast Culture in the Context of Network Culture
}

\section{Feng Wang}

Department of Arts and Sciences Jilin Agricultural Science and Technology College, Jilin, Jilin, 132101

Keywords: Northeast Cultural Network Culture, System Construction

\begin{abstract}
With the popularity of network technology, network culture and traditional campus culture have merged, changing the behavior habits, thinking patterns and value systems of teachers and students, creating a rich network of cultural activities and language exchange systems. The basic contents of Northeast regional culture research include the evolution of Northeastern nationality and the historical evolution of Northeastern regional culture, the characteristics of Northeastern regional culture and its representation, Northeastern literature and art, the blending and comparison of Northeastern regional culture and Northeast Asian regional culture, Northeastern region Culture and economic and social development in Northeast Asia, etc. Studying the regional culture of Northeast China has important academic and practical significance for the construction of Chinese cultural soft power.
\end{abstract}

\section{Introduction}

Cultural construction is the guiding force and internal thrust for promoting economic and social development. To revitalize the Northeast economy and to improve vitality and competitiveness in the Northeast, we must do our own cultural construction work, draw on the cultural essence of the Chinese nation and the times, and use the excellent traditional culture, the spirit of the times and the common culture as the background. The needs of contemporary social and economic development in the Northeast are well integrated, thus highlighting the "personality" of the Northeast economy and culture.

\section{The connotation and characteristics of network culture}

With the in-depth development of network technology and the continuous deepening of cultural exchanges around the world, the study of context has entered a diversified stage. Cultural context is not only a concept of linguistics, but also a focus on sociology, culture, history, philosophy and so on. Cultural context cannot be simply interpreted as a "cultural context." With the constant understanding of the environment in which language and language are used, it is necessary for us to interpret and think about the concept of "cultural context."

Every society has its own unique culture. In the network society, the academic circles explore the connotation and characteristics of network culture to contribute to the healthy and orderly development of the network society. However, the meaning of the network culture is far from reaching a consensus. The reason is that most scholars still stay in the network culture is an important factor in the current social development, but the network society has not yet formed. Correspondingly, the interpretation of the network culture is difficult to surpass. Network culture is the cognitive stage of network interval culture carried by network platform and network technology. Broadly speaking, network culture refers to cultural activities and cultural products with network social characteristics on the network. It is based on the creation and development of network materials, or it is considered to be the extension and display of human traditional culture and traditional morality on the Internet. In a narrow sense, network culture is a unique culture that only circulates on the Internet, or refers to spiritual creation activities and achievements based on computer technology and information network technology and network economy. It is a special world of people in the Internet. In the work, learning, communication, communication, leisure, 
entertainment, etc., the general form of the activities and the values and social mentality reflected.

However, the network society has been formed. The network culture is not only the network interval, or the culture carried by the network, but also the culture of the whole society. However, the formation of the network society is not long, and the formation of network culture has a lag. Therefore, the scientific connotation of network culture needs to strengthen research and exploration in the academic circle and the whole society. Network culture is also a human culture. We comb the scientific concept of culture from a macroscopic perspective and history, which is an important part of accurately summarizing and refining the connotation of network culture. According to the textual research, "culture" comes from the phrase "human culture", which comes from the Yijing slogan: "Rigid and soft staggered, astronomical; civilized, humanistic. Observing astronomy, changing time, viewing Humanity, to become the world." Among them, the original meaning of "text" refers to the texture of the interlaced colors. "易・系辞下》云: "The things are mixed, so the essays"; "Chemical", the original meaning for the change, generation, and creation, such as "Zhuangzi • Xiaoyao Tour": "Chemical and the bird, its name is Peng" . It can be seen that the historical, inherited and creative characteristics of culture are highlighted. Therefore, the culture in a broad sense refers to the sum of material wealth and spiritual wealth created by human beings in the practice of social history; the culture in the narrow sense is the social spiritual life form that has been produced and developed on the basis of certain material production methods in history. Sum. Based on this, we believe that the network culture is the sum of the social spiritual wealth generated and developed on the basis of certain material production methods in the network era, inheriting and innovating.

\section{Northeast Regional Cultural Content}

The regional culture of Northeast China and the diverse composition of Northeastern literature and art. From the perspective of the existing administrative region, the "Northeast Region" contains the three administrative provinces of Hei, Ji and Liao, which are culturally attributed to the "Northeast Cultural Region". However, from the actual situation, influenced by the different natural spaces, historical traditions, ethnic structures, foreign cultures and administrative divisions, a small cultural circle with different forms has been formed under the cover of "Great Northeast Culture". Regional culture nourishes regional literature and art. For the Northeast, the Northeastern culture, which is composed of many small cultural circles, also breeds Northeastern literature and art with both family similarities and colorful colors. From the morphological point of view, this includes not only the northeastern big Yangge and the northeast two-person turn, but also folklore stories, folk song and dance dramas belonging to different regions and ethnic groups, as well as the Northeast writer literature and art works that entered the literary history. From the perspective of historical development, Northeastern literature and art includes not only the literature and art of the Northeast Occupied Area, the literary art of the Puppet Manchuria, the literature of the Northern Wilderness, the literature of the educated youth, but also the contemporary Chinese mass culture. Folklore literature and art such as the Northeastern two-person turn, the Northeast essays, and the Northeast-themed film and television dramas that have far-reaching influence. In addition, a number of national writers have been produced in the Northeast. In short, the literature and art of Northeast China under the influence of the regional culture of Northeast China is not a monolithic form, but a form of pluralism, which requires a multi-level analysis from a historical perspective.

The main category of Northeast regional culture and Northeast folk culture and art. (1) Two people in the northeast and northeast essays. As a typical folk art form in the Northeast, the Northeast two people have a long history, far-reaching influence and strong vitality. They are the most important aesthetic entertainment methods in the daily life of the Northeast. Especially in the present, the northeastern two-person turn and the northeast essay have a national and even worldwide influence, which has also caused controversy between the academic circles and the private sector. The popular and popular discussion of the folk art represented by the northeastern two-person turn and the northeast essay is the current artistic function, market effect, cultural taste 
and spiritual trend of the popular culture and consumer culture. Therefore, it is necessary to increase the intensity from In theory and practice, the author deeply studies the aesthetic characteristics, social and cultural functions, and cultural industries of the Northeast and the Northeast. (2) Northeast folktales, folk dances and local operas. The terrain of the Northeast is diverse and complex, with Xiaoxing'anling in the north, Daxing'anling in the west, Changbai Mountain in the east and the southern coast. In history, Manchu, Korean, Hezhe, Oroqen, Ewenki, Daur, Hui and other ethnic minorities lived in harmony with the Han people. Various local myths, folktales, folk songs and folk songs were spread in different regions and different ethnic groups. Dances and local operas constitute a rich and diverse form of folklore in the Northeast, and still play an important role in people's lives and production.

\section{Northeast cultural construction path}

The construction and management of social culture is a new wave of management emerging in Western countries in the early 1980s and is a new scientific theory. Learning and learning from the advanced social culture of the West has also become an important way to cultivate our society and culture. The humanistic spirit, the scientific rational spirit, the democratic spirit, freedom, equality, human rights, the rule of law, the market economy, etc., contained in the modern social culture of the West, are the basic values and the most important basic concepts shared by all mankind, and are the social progress. And the most important signs and guarantees of modernization. The Northeast must follow the contemporary cultural mainstream of China, and with a more open mind, boldly bring to the best of the international social culture, use it for me, and "make it northeast." For example, the American society values the spirit of innovation, and Japanese society emphasizes teamwork. Under the new era conditions, the spirit of individual innovation is the urgent need of the knowledge economy, and the team spirit is the guarantee for the efficient operation of the social organization machines. It is necessary to adopt the strength of the family and combine the individual innovation spirit with the team spirit. Building social culture is essentially a creative process of cultural choice, cultural combination and cultural reconstruction. There are also differences in the cultural philosophy of the society between the East and the West. For example, the society of the United Kingdom and the United States emphasizes "rational" management, focusing on rules and regulations, management organizational structure, contracts, individual struggles, competition, etc., while the Eastern society emphasizes the management of "humanity", such as emphasizing interpersonal relationships and qualifications. The role of group awareness, loyalty, cooperation, etc. On the issue of rationality or emotion-based, the Anglo-American social management and East Asian social management have formed a sharp contrast, which has also formed two different social management models. These are worthy of consideration and reference to learn from each other.

In the contemporary social and cultural construction in Northeast China, the process of learning and learning from the advanced social culture of the West is also a process of abandoning the dross in traditional culture and making up for the missing basic values and ideas in our traditional culture. The problems that need to be solved and are being worked on in the construction of Northeast culture include: the rigid influence of the traditional political system, the impact of self-sufficient agricultural economy, the influence of the planned economic model, and the idea that the service consciousness has not yet been fully established, the official orientation and the seniority of the seniority. The influence of the growth of talents and the spirit of the rule of law has not yet fully established from the deep ideology to bring problems to the social and cultural construction. The idea of "speaking human feelings" harming the interests of organizations and seeking stability and chaos affects the spirit of social innovation and competition. The one-sided group concept affects the development of individual intelligence, the distribution model of egalitarianism, and the social incentive mechanism. In particular, the current social and cultural construction in Northeast China must continue to emphasize the use of international advanced cultural spirit, such as the spirit of the rule of law. Although the concept of "rule of the people" and "rule of law" in the traditional culture of Northeast China has been greatly improved, it has not been completely eradicated. 
The construction of social culture in Northeast China should conform to the requirements of the development of the times, conform to the trend of historical development, and can better reflect the characteristics of the times and the spirit. The contemporary social culture construction in Northeast China should reflect the common ideal, the spirit of collectivism, the sense of ownership, the spirit of service dedication, the spirit of science, etc. It is necessary to carry forward the spirit of unremitting struggle for the realization of socialist modernization. This is the common spiritual pillar of the whole nation. Common things. However, due to different social regions, different local environments in the same region, different historical traditions, different institutional models, different employee qualities, different social functions, scales, and social goals pursued, the time to enter the market is different. Social culture is also different.

\section{Conclusion}

The construction of a safe discourse system of network culture and socialist ideology is to expand the cultural identity of social strata in respecting differences, and to promote the consensus of social stratum in the inclusion of diversity, aiming at the effective integration of mainstream ideology and network culture diversity. Clarify the relationship between network multiculturalism and explore the specific ideological content and expression of network multiculturalism. The construction of Northeast culture is a construction project that has both a source that can be tapped and a complex system that needs to highlight its own characteristics. It is necessary to actively learn from China's excellent culture, the advanced culture of East and West, and the spirit of advanced culture with commonality according to its own reality. Convergence and promotion work to build a vibrant and distinctive Northeast culture.

\section{Acknowledgements}

Project Fund: Jilin Province Social Science Fund Project, project number: 2018W14

\section{References}

[1] Fu Yongchun. The socialized guiding strategy of college students' values under the network environment [J]. China Higher Education, 2013 (, 11).

[2] Zhang Yanfei. How to deal with the impact of network culture on college students' ideological and political education[J]. Journal of Fujian Radio and Television University, 2010(, 3).

[3] Zuo Wei, Qin Xia, Shan Xiaofeng, Wang Jun. Problems in University Campus Network Culture and Its Influence on Ideological and Political Education [J]. Jiangsu Higher Education, 2010 (, 5).

[4] Jiang Hongda. On the Innovation of College Students' Ideological and Political Education Methods under the Network Environment[J]. School Party Construction and Ideological Education, 2010(, 23). 